\title{
The Moderating Influence of Industry Competition on the Relationship between Corporate Strategy and Organizational Performance
}

\author{
Bruce J. Ogaga ${ }^{1}$, Owino Odhiambo Joseph ${ }^{2}$ \\ ${ }^{I}$ Department of Business Administration, University of Nairobi, Kenya \\ ${ }^{2}$ Department of Business Administration, University of Nairobi, Kenya \\ *Corresponding Author: Bruce J. Ogaga, Department of Business Administration, University of \\ Nairobi, Kenya \\ Received Date: 07-07-2017 \\ Accepted Date: 14-07-2017 \\ Published Date: 24-07-17

\begin{abstract}
The influence of strategic choice on performance is a subject of debate in strategic management. However, previous studies have yielded inconsistent results. While industrial organization economics theory and the contingency theory emphasize the role of industry environment in organizational performance, little research attention has been directed towards investigating the indirect influence of the competitive environment on performance. The current study, attempts to highlight the indirect influence of the environment by testing the moderating influence of industry competition on the relationship between corporate strategy and performance. The study adopted the descriptive cross sectional survey with data collected from companies listed at the Nairobi Securities Exchange. Structured questionnaire was used and data analyzed through both descriptive and inferential statistics and linear regression. The findings demonstrate that industry competition has a significant moderating influence on the relationship between corporate strategy and performance. Drawing from the findings, we conclude that performance of the firm depends on the degree of alignment of corporate strategy to industry competition.
\end{abstract}

Keywords: Corporate strategy, industry competition, performance

\section{INTRODUCTION}

Organizational success seldom depends upon a single factor, but on complex interactions between a combination of several factors from within and outside the firm. The internal business environment determines how the firm manages performance through the configuration and deployment of resources (Leitao \& Franco, 2008; Okeyo, 2013). Thus, organizations need to establish the conditions and forces that affect performance in the market. Porter (1985) visualized strategy as the search and realization of a favourable competitive position in the industry. Corporate strategy specifies actions taken by a firm to gain competitive advantage in different products and markets (Ireland, et al., 2013). Corporate strategy guides the deployment of resources and organizational capabilities across the markets within which the firm competes. Strategic leadership is a prerequisite for effective navigation of the business in the competitive landscape.
Every firm competing in an industry crafts competitive strategy whether explicit or implicit (Porter, 1980). Barnet et al. (1994) argue that competitive forces spawn distinctive competences, but managers attempt to manage these forces by seeking positional advantage. Strategic choices are made by managers within the underlying industry competition context. Despite the fact that strategy is crafted to counter the influence of competition on corporate performance, more often, strategic decisions are made based on hunch without scientific knowledge about the magnitude of competitive influence on performance outcomes. Although the influence of strategy on corporate performance is not in doubt, the implementation of corporate strategy is fraught by multiple dilemmas particularly in volatile markets characterized by dynamic competition. Furthermore, the success of corporate strategy is tested by its versatility to manage emerging threats and accomplish planned performance 
outcome. Although previous studies (Rumelt, 1995; Porter, 1996; Owino, 2014) have reported significant findings pertaining to the influence of industry competition on performance, the results are inconsistent both in the direction and magnitude of the influence of industry competition on organizational performance. Besides, contradictory findings are commonplace in empirical literature pertaining to the effects of corporate strategy on performance. Furthermore, limited attempt have been made to test the moderating influence of industry competition on the relationship between corporate strategy and performance. Thus, the central focus of our study is to determine the influence of industry competition on the relationship between corporate strategy and performance.

\section{THEORETICAL BASIS OF THE STUDY}

The industrial organization economics theory stipulates that organizations achieve high performance when there is a fit between organizational strategy and the environment in which it operates (Porter, 1980, 1981; Parnell, 2013). The theory posits that there is a causal link between the structure of the industry in which an organization operates and the choices adopted by the organization to manage its performance. Corporate strategy influences the way a firm deals with competition to safeguard its market segment, attract more customers from rival firms and consequently improve its performance both in the short and long term. The strategic choices made by the firm depict relevance in the market and competitiveness within the industry. The industrial organization paradigm views profitability as a primary function of firms with a high concentration of competitors and relative homogeneity (Chandler, 1962). The game theory argues that one competitor's move is likely to galvanize response from another, and the outcome of choices made by a firm is dependent upon the choices made by its rivals in the industry. Game theory is thus concerned with the interrelationships between the competitive moves of a set of competitors (Johnson et al., 2008; Lussier, 2013; Grant, 2013; Karami \& Tajvidi, 2016). Game theory offers insight that allows the modeling of competition as a process of interactive decision making by rivals (Grant, 2013). It permits the framing of strategic decisions by providing the structure and lens for understanding competitive situation in terms of the identity of players; specification of each player's options; pay off from their strategic choices; and the sequencing of decisions that may lead to enhanced competitive position.

The contingency theory underscores the role of strategic alignment which enhances the fit between an organization's strategic priorities and its environment. In turn, the matching of organizational resources with opportunities in the market leads to improved organizational performance (Morton \& $\mathrm{Hu}, 2008$; Okeyo, 2013). The underlying construct of strategic fit is fundamental as it leads to a higher level of organizational consensus associated with improved coordination and cooperation in the strategy and ultimately with organizational performance (Walter et al., 2013). Therefore, organizational performance is the outcome of alignment of corporate strategy to the competitive environment and market conditions.

\section{CORPORATE STRATEGY, INDUSTRY Competition ANd Performance}

Corporate strategy deals with the broad and long term direction of the firm in matters concerning growth, stability or retrenchment (Parnell, 2010). Zenger (2013) describes corporate strategy as a process of discovering and targeting attractive markets and then crafting positions that deliver sustained competitive advantage in them. Companies achieve these positions by configuring and arranging resources and activities to provide either unique value to customers or common value at uniquely low cost. Powell (2003) avers that factors within the industry explain 17 to 20 percent of the variance in organizational performance. Porter (1981) presumed a direct link between industry's structural attributes and organizational performance. To illustrate the importance of industry structure, Barney (1991) identified product differentiation and overall elasticity of market demand as the key industry attributes that affect performance. Hence, superior performance can be pursued by firms through product differentiation, building strong brand reputation and creating good relations with customers in the chosen market. Since changes in the industry competition are difficult to predict with certainty, the competitive business landscape requires building core competences and strategic leadership for survival, superior performance and sustained market leadership (Hitt et al., 2011). By the same token, Sabourin (2015) concluded that the execution of corporate strategy has significant influence on 
performance of the firm. Nevertheless, firms cannot have complete information for accurate prediction of competitive dynamics at a future date. This creates uncertainty that weakens strategic options and as a consequence, it may negatively affect performance.

For the purpose of analysis, industry competition was conceptualized using Porter's five force framework characterized by the number of sellers; the degree of product differentiation; market entry and exit conditions; and resource mobility (Porters, 1981). According to Porter (1981),industry

structure grows out of a set of economic and technical characteristics that determine the strength of competitive forces in an industry, and that structure drives competition and profitability. Schmidt (2010) argues that competition increases the risk of revenue loss by firms in the industry. Hence, competition generates strong incentives for company survival and forces managers to increase counter efforts that lead to improved organizational performance (Nickell, 1996). Miller et al. (1982) further, showed that competition has a major impact on corporate strategies. Competition may trigger increased spending on research and development. As a result, research output may enhance a firm's differential advantage, leading to improved performance.

Failure by firms to respond to competition may create pressure for market exit by firms. Therefore, companies adjust their strategies as the competitive environment change (Henderson $\&$ Mitchell, 1997).The notion is that companies must adopt a more dynamic strategy to defend themselves against competitive maneuvers and increase their market share. While strategy is based on market conditions, it interacts with organizational capabilities to influence performance of the firm. Therefore, competitive threats require prudent corporate strategies in order to attain sustainable competitive advantage and superior performance (White, 2000; Ignatius, 2015). From the foregoing debate, we hypothesize as follows:

Industry competition has significant moderating influence on the relationship between corporate strategy and performance

\section{ReSEARCh Methodology}

The descriptive cross sectional census survey design was adopted in the study. Since the population of interest in our investigation was small, the research design targeted all the companies listed in the Nairobi Securities Exchange. Cross section survey designs are relevant for testing and describing the association between variables. Sixty three firms listed at the Nairobi Securities Exchange constituted the sample frame. A structured questionnaire was developed based on measurement scales borrowed from literature (Neuman, 2007; Machuki \& K'Obonyo, 2011; Dauda et al.2010). All the variables were measured using a 5-point rating scale with anchors $1=$ not at all; and $5=$ very large extent. We subject the research instrument to reliability test before commencing data collection. Feedback from the pilot test was used to refine the questionnaire. Reliability was tested by computing Cronbach's Alpha coefficients. The results of reliability scores were as follows: Corporate strategy had a reliability score of 0.765; industry competition yielded a score of 0.872 , and organizational performance recorded a score of 0.763 . Our reliability scores were above the minimum acceptable limit of 0.7 (Nunally, 1978).

Corporate strategy was tapped through the generic forms consisting of cost leadership, differentiation and focus. Industry competition was measured in accordance with Porter's five forces framework namely threat of entry, buyers' bargaining power, suppliers' bargaining power, rivalry within the industry and threat of substitute products (Porter, 1980). Organizational performance was measured using the balance scorecard framework. The measurement scale for the dimensions of balance score card comprised perceptual indicators that involved asking respondents to rate the performance of their firm on the basis of internal business processes, customer satisfaction, learning and growth as well as financial perspective in comparison to competing firms in the industry. Data were collected using structured questionnaire targeting top managers including finance director, marketing director and operations director.

Data were analyzed by first computing composite standardized scores of each variable. For purposes of testing the hypothesis of our study, we computed an interaction term by multiplying standardized scores of corporate strategy by industry competition. Before commencing hypothesis tests, we tested for the assumptions of linear regression including 
linearity, normality, homogeneity and multicollinearity. The results of our diagnostic tests showed that the data met all the assumptions of linear regression. Therefore, we proceeded to test our hypothesis through linear regression analysis. We used hierarchical regression analysis to test our hypothesis. We first regressed corporate strategy on organizational performance. In the second step, we introduced industry competition in the regression model. In the third stage, we introduced the interaction term in the regression model. The results of our tests are reported below.

\section{FINDINGS}

\section{Descriptive Results}

Out of the targeted 63 firms, 46 turned in analyzable data translating to a response rate of $73 \%$. Majority of the respondent firms (60\%) had employees ranging between 100 and 500 . The size of firms measured by number of permanent employees was on average, wherein only $9 \%$ of the firms employed more than 1000 people. The mean scores of corporate strategy ranged between 2.83 and 4.52. The question assessing the degree of product differentiation obtained the lowest mean score of 2.83, indicating that majority of the firms had comparable and less differentiated products across the industries. The question tapping the extent at which trade agreements are signed by competing firms had a mean score of 4.52, suggesting that strategic partnership and alliances were a common practice across the industries. Other questions that attracted high mean score included the presence of innovative organizational culture (mean $=4.41$ ) and the pursuit of diversification strategy (mean $=4.33$ ).

The results of mean scores for industry competition ranged between 2.83 and 4.41 . In spite of the weak product differentiation, a contradictory finding was the low threat of substitute products (mean $=2.83$ ). In tandem with industrial organization economics theory, we expected a high mean score for the threat of substitute products to justify the weak differentiation across the industry. Competition for inputs appeared to be stiff as evidenced by a mean score of 4.41. The erection of market entry barriers attracted a mean score of 4.41 indicating that firms tend to fend off competition by making it difficult for new entrants to penetrate the industry. The practice of price wars (mean $=4.33$ ) and adoption of innovative technologies pervade the organizations across the industries. The results suggest that intensity of competition on the one hand pile pressure on profit margins and on the other hand force firms to pursue innovation as the path towards differentiation and creation of competitive advantage. Organizational performance was strongly reflected through employee training and development $($ mean $=4.52)$; social responsibility programmes $($ mean $=4.46)$; and diversity and inclusivity in staff recruitment (mean $=4.43$ ). However, weak performance was evident in the area of employee motivation $($ mean $=2.83)$

\section{The Moderating Influence of Industry Competition on the Relationship between Corporate Strategy and Performance}

To assess the moderating effect, the study applied hierarchical regression method as underscored by Baron and Kenny (1986) as well as Aiken and West (991). Baron and Kenny (1986) defined a moderator as a variable that affects the direction and strength of the relationship between a predictor and a criterion variable. They posit that moderation can only be supported if indirect influence of the independent variable on the outcome variable is significant. Composite scores were computed for each of the variables. As a first step in the test process, corporate strategy was regressed on organizational performance. The results obtained were statistically significant. In the second step, industry competition was introduced to the model. In the final step, the product term of corporate strategy and industry competition was introduced to the model. The moderation effect was examined by checking the change statistics $\left(\Delta \mathrm{R}^{2}, \quad \mathrm{~F}\right.$ statics), the significance of the interaction term and model coefficients. The significance of the interaction term was evaluated when controlling for corporate strategy and industry competition. The results obtained are reported in Table 1.

Table1. Moderation effect of industry competition on the relationship between corporate strategy and nonfinancial performance

\begin{tabular}{|c|c|c|c|c|c|c|c|c|c|}
\hline \multicolumn{10}{|c|}{ Model Summary } \\
\hline \multirow{2}{*}{$\begin{array}{l}\text { Mode } \\
1\end{array}$} & \multirow[t]{2}{*}{$\mathrm{R}$} & \multirow{2}{*}{$\begin{array}{c}\mathrm{R} \\
\text { Square }\end{array}$} & \multirow{2}{*}{$\begin{array}{l}\text { Adjusted R } \\
\text { Square }\end{array}$} & \multirow{2}{*}{$\begin{array}{l}\text { Std. Error of } \\
\text { the Estimate }\end{array}$} & \multicolumn{5}{|c|}{ Change Statistics } \\
\hline & & & & & R Square Change & F Change & df1 & df 2 & Sig. F Change \\
\hline 1 & $.882^{\mathrm{a}}$ & .778 & .773 & .20191 & .778 & 153.820 & 1 & 44 & .000 \\
\hline 2 & $.929^{\mathrm{b}}$ & .863 & .857 & .16035 & .085 & 26.759 & 1 & 43 & .000 \\
\hline
\end{tabular}


The Moderating Influence of Industry Competition on the Relationship between Corporate Strategy and Organizational Performance

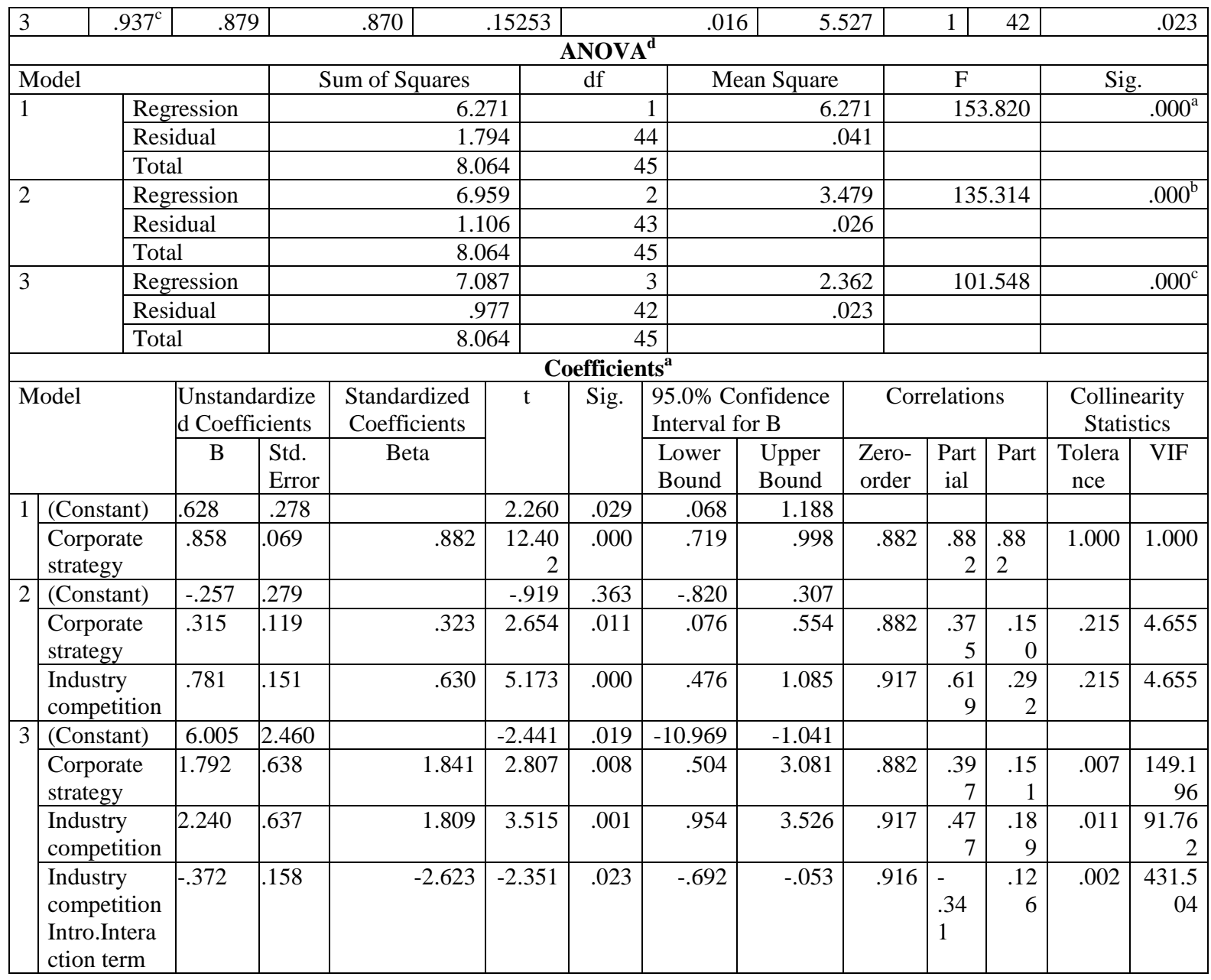

a. Dependent Variable: Nonfinancial performance

a. Predictors: (Constant), Corporate strategy

b. Predictors: (Constant), Corporate strategy, Industry competition

c. Predictors: (Constant), Corporate strategy, Industry competition, industry competition

The results in Table show that the relationship between corporate strategy and non financial performance was statistically significant. The results demonstrate that corporate strategy statistically explained 77.8 per cent of the variation in performance $\left(\mathrm{R}^{2}=0.778\right)$. When industry competition was introduced into the model, the explained variation in performance improved by $8.5 \%\left(\mathrm{R}^{2}=0.085\right)$ suggesting that industry competition had positive influence on performance. When the product term of corporate strategy and industry competition was introduced in the model (Model 3), the results obtained were statistically significant ( $\mathrm{p}$-value $=$ 0.023; F Statistics $=101.548$ ). The results of our findings demonstrate that industry competition moderates the relationship between corporate strategy and firm performance. Thus, our hypothesis was supported. The negative beta coefficient (Std. beta $=-2.623$ ) illustrates an inverse relationship implying that increased competition in the industry had negative effect on the influence of corporate strategy on performance.

\section{DISCUSSION}

Previous studies have treated competition as a performance constraint that can be managed by strategists and converted to opportunities for growth (Prescott, 1986). Therefore, understanding competition in the industry in which an organization operates can yield positive influence, especially when organizations are able to create new forms of competitive advantage (Prahalad \& Hamel, 1990). Wu, Gao and Gu (2015) argue that industry competition can significantly affect corporate strategy. In the current study, it was established that industry competition moderates the relationship between corporate strategy and performance. The findings are consistent with the results obtained by Prescott (1986) who revealed that competitive environment modified the strength of the relationship between strategy 
and performance. However, unlike Prescott (1986) who concluded that competition modified the strength, but not the form of the relationship between strategy and performance, our findings suggest that industry competition affects both the direction and strength of the relationship between corporate strategy and performance. However, the results contradict Ondari (2015) whose findings revealed that competitive environment has no significant effect on the relationship between diversification strategy and performance of NSE listed companies. The findings further disagree with Owino (2014) who concluded in his study that competition had no significant moderating influence on the relationship between organizational culture and non financial performance of micro financial institutions in Kenya. While he maintained that competition has a direct effect on performance, our study illustrates that industry competition moderates the influence of strategy on performance.

In highly competitive industries, firms constantly jockey for advantage as they launch strategic actions and respond or react to rivals moves (Derfus, et al. 2008). The central brute empirical fact in strategy is that some firms outperform others (Jelsky, et al. 2007), meaning that, competitive rivalry influences an individual firm's ability to gain and sustain competitive advantage (Powell, 2003). Rivalry results from firms initiating their own competitive actions and responding to actions taken by competitors (Sirmon, et al. 2008; Grant, 2013). As competition intensifies, managers attempt to align strategy to the environment (Henderson \& Mitchell, 1997) with the aim of creating competitive advantage over rivals. Whereas, substantial number of firms may modify their strategies to deal with changes in the competitive environment, intense competition may force weak firms to exit the market. As weaker firms exit, the intensity of competition slows and the market adjusts to accommodate firms that have survived the competition. Therefore, the influence of industry competition on the relationship between corporate strategy and performance is complex and depends on market size to the extent that competition may have negative effect as the market size reduces. Consequently, firms based in larger markets outperform their rivals situated in smaller markets when they compete in common locations. Therefore, we hold the position that industry competition interacts with strategy to influence performance of the firm, but the direction and size of the moderation by industry competition depends on market size.

Our findings support the industrial organization economics theory on the basis that corporate strategy is the process of realigning the firm to the competitive environment to improve organizational performance. Consistent with the industrial organization economics theory supposition that there is a causal link between industry structure and strategic choices, our findings demonstrate that the moderating influence of industry competition may force firms to adjust corporate strategy as the competitive landscape changes in the hope that the modified strategy creates competitive advantage and delivers superior organizational performance. Our findings also support the contingency theory by pointing out that since industry competition significantly moderates the relationship between corporate strategy and performance, the choice of strategy to a large extent depends on the structure of the industry and intensity of competition in the market.

\section{CONCLUSION}

We have empirically demonstrated that industry competition significantly affects the influence of corporate strategy on performance. Our results reveal that competition has significant negative moderating influence on the relationship between corporate strategy and performance. The results illustrate that industry competition affects both the direction and magnitude of the relationship between corporate strategy and performance. We therefore conclude that the performance of the firm depends on the extent to which corporate strategy is aligned to competitive environment. We further conclude that superior organizational performance is dependent on how well managers monitor the competitive environment, gather market intelligence and craft competitive strategy that deliver superior value to customers.

\section{REFERENCES}

[1] Aiken, L. S. \& West, S. G. (1991). Multiple Regression: Testing and Interpreting Interactions. Thousand Oaks, CA: Sage.

[2] Ataullah, A., Davison, I., Lee, H. \& Wood, G. (2014). Corporate Diversification Information Asymmetry and Insider Trading. British Journal of Management. 25, 223-251.

[3] Barnett, P.W., Greeve, R.H. \& Park, Y.D. (1994). An Evolutionary Model of 
The Moderating Influence of Industry Competition on the Relationship between Corporate Strategy and Organizational Performance

Organizational Performance. Strategic Management Journal, 15, 11-28.

[4] Barney, B.J. (1986). Types of competition and the theory of strategy: Toward an integrative framework. The Academy of Management Review, 11(4), 791-800

[5] Barney, B.J. (1991). Firm Resources and Sustained Competitive Advantage. Journal of Management, 17(1), 99-120.

[6] Baron, R.M., \& Kenny, D.A. (1986). The moderator-mediator variable distinction in Social Psychological research: Conceptual, Strategic and Statistical Considerations. Journal of Personality and Social Psychology, 51, 11731182.

[7] Beard, W.D. \& Dess, G.G. (1981). Corporatelevel strategy, business-level strategy and firm performance, The Academy of Management Journal, 24(4), 663-688

[8] Chandler, A. D. (1962). Strategy and Structure. Chapters in the History of the Industrial Enterprise. Cambridge, MIT Press.

[9] Dauda, Y.A., Akingbade, W.A. \& Akinlabi, (2010). Strategic Management Practice and Corporate Performance of Selected Small Business Enterprises in Lagos Metropolis. International Journal of Business and Management, 5 (7)

[10] Derfus, P. J., Magitti, P.G., Grivim, C, M. \& Smith, K.G. (2008). The Red Queen effect. Competitive actions and firm Performance. Academy of Management Journal, 51, 61-80.

[11] Grant, R.M. (2013). Contemporary Strategy Analysis John Wiley \& Sons Ltd. W. Sussex, U.K.

[12] Henderson, R. \& Mitchell, W. (1997). The interactions of organizational and competitive influences on strategy and performance. Strategic Management Journal, 18 (Summer), 5-14

[13] Hitt, M.A., Ireland, R.D. \& Hoskinsson, R.E. (2011). Strategic Management: Competitiveness and Globalization. Boulevard: South West Cengage Learning.

[14] Ignatius, A. (2015). The Discipline of Business Experimentation. Harvard Business Review, April, 35-43.

[15] Ireland, R. D., Hoskisson R. E. \& Hit, M.A. (2013).The Management of Strategy Concepts and Cases. South Western, Cengage Learning, Canada.

[16] Jelsky, J. W. Goes, J. \& Baburogh, O.N. (2007). Contrasting perspectives of Strategy Making: Applications in hyper environments. Organization Studies, 28 (1), 71-94.

[17] Johnson, G., Scholes, K. \& Whittington, R. (2008).Exploring Corporate Strategy. Prentice Hall.
[18] Karami, A. \& Tajvidi, M. (2016). Product Development Strategy: Innovation Capacity and Entrepreneurial Firm Performance in High Tech SME. Springer. ISBN 11137501391, 9781137501394. Amazon.com.

[19] Kim, W.C. \& Mauborgne, R. (2015). Blue Ocean Strategy. How to Create Uncontested Market Space and Make Competition Irrelevant. Harvard Business Press United States.

[20] Leitao, J. \& Franco, M. (2008). Individual entrepreneurship capacity and performance of SME's, at: http://ssm.com.

[21] Lussier, R.N. (2013). Management Fundamentals, Springfield College, Springfield Massachusetts.

[22] Machuki, V.N. \& K'Obonyo, P.O. (2011). Organizational Strategic Behaviour and Performance of Publicly Quoted companies in Kenya. Prime Journals: Business Administration and Management, 1(7) 219-232.

[23] Miller, D., Kets deVries, M. F. R. \& Toulouse, J. M. (1982). Top executive locus of control and its relationship to strategy making, structure and environment. The Academy of Management Journal, 25(2), 237-253.

[24] Morton, N.A., \& Hu, Q. (2008). Implications of the fit between organizational structure and Economic Resource Planning: A structural contingency theory perspective. International Journal of Information Management, 28,391402.

[25] Neuman, L.W. (2007). Social Research Methods: Qualitative and Quantitative Approaches, 7th Edition, London: Pearson International Edition.

[26] Nickell, S.J. (1996). Competition and corporate performance. Journal of Political Economy, 104 (4), 724-746.

[27] Nunnally, P. (1978). Psychometric theory.2nd Edition New York, McGraw Hill.

[28] Okeyo, W. (2013). Entrepreneurial Orientation, Business Environment Business Development Services and Performance of small and Medium Manufacturing Enterprises in Kenya. Unpublished PhD. Thesis, University of Nairobi.

[29] Ondari, E.N. (2015). Effect of Top Management Team Diversity and Competitive Environment on the Relationship between Diversification Strategy and Performance of Companies Listed in The Nairobi Securities Exchange. Unpublished PhD. Thesis. University of Nairobi.

[30] Owino, J.O. (2014). Organizational Culture, Marketing Capabilities, Market Orientation, Industry Competition and performance of Microfinance Institutions in Kenya. Unpublished PhD. Thesis. University of Nairobi. 
The Moderating Influence of Industry Competition on the Relationship between Corporate Strategy and Organizational Performance

[31] Parnell, J.A. (2010). Strategic clarity, business strategy and performance. Journal of Strategy and Management, 3(4), 304-324

[32] Parnell, J.A. (2013). Uncertainty, Generic Strategy, Strategic Clarity and Performance of Retail SME in Peru, Argentina, and the United States.

[33] Porter, M. E. (1980). Competitive Strategy, New York, Free press.

[34] Porter, M. E. (1981). The Contributions of industrial organization to strategic management. Academy of Management Review, 6, 609-620.

[35] Porter, M. E. (1985). Competitive Advantage: Creating and Sustaining Superior Performance. New York: Free Press

[36] Porter, M.E. (1996). What is Strategy? Harvard Business Review August - September, 58-79.

[37] Powell, T.C. (1996). How much does industry matter? An alternative empirical test. Strategic Management Journal, 17, 323-34

[38] Powell, T.C. (2003). Varieties of Competitive Parity. Strategic Management Journal, 24, 6186

[39] Prahalad, C.K. \& Hamel, G. (1990). The Core Competence of the Corporation. Harvard Business Review, 68, 71-91.

[40] Prescott, E.J. (1986). Environments as Moderators of the Relationship between strategy and performance. The Academy of Management Journal, 29(2), 329-346

[41] Rumelt, R.P. (1995). How much does Industry Matter? Strategic Management Journal, 12(3), 167-185, Detroit.

[42] Ryall, M. D. (2013). The new dynamics of competition. An emerging science for modelling strategic moves. Harvard Business Review, 80-87.

[43] Ryals, 1. \& Payne, A. F. T. (2001). Information empowered relationship marketing: Leveraging customer information financial services. Journal of Strategic Marketing 9,1-25

[44] Sabourin, V. (2015). Strategy execution: five drivers of performance. Journal of Strategy and Management, 8(2), 127-138

[45] Saunders, M., Lewis, P., \& Hill, A.T. (2009). Research Methods for Business Students. England: Prentice Hall.
[46] Saunders, M.N.K., Lewis, P., Thornhill, A., \& Bristow, A.(2015). Understanding Research Philosophies and Approaches: Research Methods for Business Students. $7^{\text {th }}$ ed., Harlow: Pearson Education, England.

[47] Selznick, P. (1957). Leadership Administration. A Sociological Interpretation. Evanstone, I. L Row, Peterson.

[48] Schaltegger, S. \& Ludeke-Freund, F. (2011). The Sustainability Balanced Scorecard: Concept and the case of Hamburg airport. http//ssm.com/abstract $=2062320$.

[49] Schendel, D.E. Hofer, C.W. (1979). Research Needs and Issues in Strategic Management.

[50] Schmidt, K.M. (1994). Managerial Incentives and Product Market Competition. Discussion Paper No. A-430. Bonn: Univ. Bonn, Wirtschaftspolitische Abteilung

[51] Schmidt, A.M. (2010). Strategic Planning and Corporate Performance. What is the relationship? Department of Management Journal, 82-100, Aarthus, Denmark.

[52] Sirmon, D.G., Gove, S. \& Hitt, M.A. (2008). Resource Management in dyadic competitive rivalry: The effects of resource building and deployment. Academy of Management Journal, 51, 919-935.

[53] Walters, B.A., Jiang, J.J. \& Klein, G. (2013). Shelter in Storm: Marketing Strategy as moderated by the hostile environment. Marketing Intelligence and Planning Journal, 23(7) 630-686.

[54] White, D.G. (2000).Industry Competitiveness and Firm Performance, Economic Review (Federal Reserve Bank of Atlanta), 70 (9), 1425

[55] Wu, P., Gao, L. \& Gu, T. (2015). Business strategy, market competition and earnings management: Evidence from China, Chinese Management Studies, 9(3), 401-424

[56] Xiao, Q., O’Neill, W.J. \& Mattila, S.A. (2012). The role of hotel owners: the influence of corporate strategies on hotel performance. International Journal of Contemporary Hospitality Management, 24(1), 122-139

[57] Zenger, T. (2013). What is the theory of your firm? Harvard Business Review, 73-79.

Citation: Bruce, J. Ogaga, and Owino Odhiambo Joseph. "The Moderating Influence of Industry Competition on the Relationship between Corporate Strategy and Organizational Performance. "International Journal of Research in Business Studies and Management, vol 4, no. 4, 2017, pp. 13-20.

Copyright: () 2017 Bruce, J. Ogaga et al. This is an open-access article distributed under the terms of the Creative Commons Attribution License, which permits unrestricted use, distribution, and reproduction in any medium, provided the original author and source are credited. 